\title{
Integration of services for elderly people reduced costs and use of health services
}

\author{
Bernabei R, Landi F, Gambassi G, et al. Randomised trial of impact of model of integrated care and case management for older \\ people living in the community. BMJ 1998 May 2;316:1348-51.
}

\section{Question}

Does the integration of medical and social services with case management programmes reduce functional decline, admissions to institutions, and the use and costs of health services in frail, elderly people living in the community?

\section{Design}

Randomised controlled trial with 12 months follow up.

\section{Setting}

A town (Rovereto) in northern Italy.

\section{Patients}

200 adults (mean age 81 y, $71 \%$ women) who were $\geqslant 65$ years of age and received home health services or home assistance programmes.

\section{Intervention}

Patients in the intervention group $(n=100)$ received case management and care planning by the community geriatric evaluation unit (which included a geriatrician, a social worker, and several nurses), case managers, and general practitioners (GPs). Case managers did the initial assessment, reported it to the geriatric evaluation unit which determined the services that patients were eligible for, and designed and implemented individualised care plans in consultation with GPs. Case managers did assessments every 2 months and were constantly available to deal with problems, monitor the provision of services, and to coordinate extra help as requested by patients and GPs. The multidisciplinary team discussed problems emerging from home visits during weekly meetings. Patients in the control group $(n=100)$ received standard care, which included GP ambulatory and home visits, nursing and social services, home aids, and meals on wheels.

\section{Main outcome measures}

Physical and cognitive function, admission to an institution, and use and costs of health services.

\begin{abstract}
Main results
After results were adjusted for baseline values, integrated care led to better functional outcomes than did standard care (Activities of Daily Living adjusted mean score 2.0 v 2.6, $\mathrm{p}<0.001$; Instrumental Activities of Daily Living adjusted mean score $4.1 \mathrm{v}$ 4.4, $\mathrm{p}<0.05$; Short Portable Mental Status Questionnaire adjusted mean score $2.8 v 3.4, \mathrm{p}<0.05$; and Geriatric Depression Scale adjusted mean score $10.9 v 12.8, \mathrm{p}<0.05)$. Compared with standard care, integrated care led to fewer admissions to acute hospitals $(p<0.05)$, nursing homes or hospitals $(p<0.01)$, or emergency departments $(\mathrm{p}<0.03)$; no effect was seen for admissions to nursing homes alone. Elderly adults who received integrated care had a shorter length of stay in nursing homes (1087 $v 2121 \mathrm{~d}$ ) or acute hospitals (894v $1376 \mathrm{~d}$ ) than did those who received standard care. Integrated care led to a 23\% savings in total per capita healthcare costs.
\end{abstract}

\section{Conclusion}

In frail, elderly people who lived in the community, case management and care planning that integrated social and medical services reduced functional decline, admissions to institutions, and costs.

\section{Sources of funding: Progetto Finalizzato Invecchiamento; National Research Council.}

For correspondence: $\operatorname{Dr} R$ Rernabei, Istituto di Medicina Interna e Geriatria, Università Cattolica del Sacro Cuore, 00168 Rome, Italy. Fax +3963151911.

A modified version of this abstract appears in Evidence-Based Mental Health.

\section{Commentary}

The study by Bernabei et al has similar outcomes to a comparable study done in the UK in $1986 .{ }^{1}$ Both studies were scientifically structured using valid methodologies. The Bernabei study had a slightly larger sample. The essence of case management is coordination of responsibility among various health professionals. Such coordination should counter service fragmentation, prevent patients from "falling between the cracks" of health care and social services, and reduce the risk that they are forgotten. Case management should provide care that is tailored to meet individual needs. Interprofessional collaboration is therefore a prerequisite for such schemes.

Strengths of this study include random allocation of patients to groups ensuring that the groups were balanced for patient age and sex; assessment of outcomes by individuals unaware of patient assignments; and follow up of all study patients for 1 year. Limitations include awareness by professionals of the assignment of patients to either group (although they were kept blind to outcomes being studied and length of follow up) and provision of care to control and intervention patients by the same GPs, which may have introduced contamination bias.

A geriatrician, social worker, GPs, and nurses were involved in the community geriatric evaluation unit in northern Italy. The close collaboration among these professionals was critical to the success of the intervention. The exact role of the nurses was not defined but all these professions should be an integral part of such a scheme. In fact, the background of the case managers was not specified-just the necessity of training to enable case managers to design care plans and coordinate all agencies involved.

If community nurses were to take on the role of case manager, they would require further training. This study shows that case management with integrated social and medical care is an effective and economic way to allow older infirm people to remain in their own homes. Implementation of such projects on a wide scale will have implications for the training of all community personnel.

Olivia Brittian, RGN, HV Lecturer, Nursing and Midwifery School University of Glasgow, Glasgow, UK

1 Davies B, Challis D. Matching resources to needs in community care: an evaluated demonstration of a long-term care model. Aldershot, UK: Gower, 1986. 